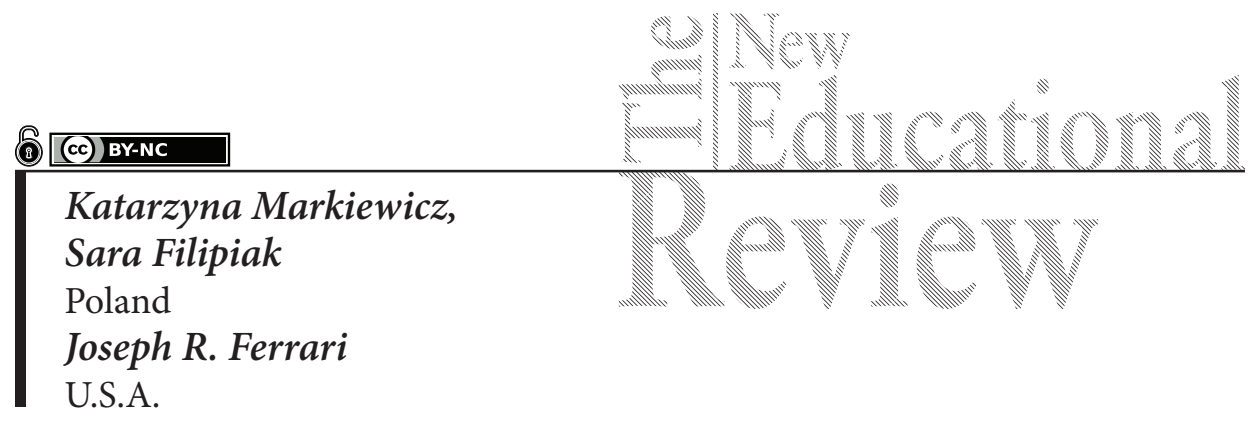

\title{
Exploring the Impact of Cultural Diaspora on Procrastination by Gender and Age
}

DOI: 10.15804/tner.2019.57.3.02

\begin{abstract}
The study aimed at discovering whether gender, age, and different cultural background may be associated with procrastination. Therefore, procrastination tendencies by students of Polish nationality residing in Poland with Polish students living in Austria were compared. All participants completed the Pure Procrastination Scale that measured the degree of self-reported procrastination. Results revealed higher procrastination scores by emerging adults living in Poland than Austria. Males from the Polish diaspora reported more procrastination behaviors than females. In contrast, procrastination was higher among Polish female than male citizens. Delaying tasks were higher in older than younger respondents within the Polish sample; for students in the Polish diaspora, procrastination decreased with age.
\end{abstract}

Keywords: procrastination, adolescence, students, Poland, Austrian diaspora, culture

\section{Introduction}

People delay and put things off for different reasons, and often for reasons more than laziness or fatigue (see Ferrari, \& Tibbett, 2017). Among students, delay of academic assignments may be because they feel the need to find additional data to perform the task on an optimal level of performance. Psychological studies revealed biological and socio-cultural determinants of procrastination. Adherents 
of biological grounds for procrastination concentrate upon genetic (Gustavson, et al., 2017; Gustavson, \& Miyake, 2017), and temperamental factors (Steel, 2007; Strenze, 2007), as well as the maturational lag of the frontal lobes and consequent disorders in executive functions, leading to inability to perform goal-oriented actions (Gustavson, \& Miyake, 2017; Rabin, Fogel, \& Nutter-Upham, 2011). Since the frontal lobes are the last brain structures to attain maturity, several studies have concentrated on the interrelations between age and procrastination behaviors (Beutel, et al., 2016; Steel, 2007; Steel, \& Ferrari, 2013). Petrill (1997) argues that executive functions, which are closely connected to the behavioral aspect of procrastination, depend both upon hereditary (molar) and environmental (modulary) factors.

The behavioral approach to procrastination connects disorders of the self-regulatory system with an impulsive need for immediate reinforcements as the most important predictor of procrastination (Tice, \& Bratslavsky, 2000; Tappolet, 2010; Sirois, 2004). Lack of motivation (Steel, \& König, 2006; Steel, \& Weinhardt, 2018), as well as treating tasks as aversive (Blunt, \& Pychyl, 2000; Evans, Baer, \& Segerstrom, 2009), are also considered to be important behavioral predictors of procrastination. At the same time, Steel (2007) argues that gender, nationality and a place of residence are significant factors associated with procrastination. Findings of a Japanese study revealed differences between younger adults and middle aged and older adults but not between gender (Nomura, \& Ferrari, 2018) but other studies did not confirm those differences (Ferrari, Özer, \& Demir, 2009).

\section{Cultural differences between Poland and Austria}

Although both Poland and Austria are members of the European Union, cross-cultural psychological research situates them in different locations (Compare Countries, 2018). Austria is an industrialized country with a well-developed economy and democratic institutions. The emphasis here is placed upon individual success and persistence in action; hence, individual targets are more important than group objectives (Triandis, 1995; Triandis, \& Gelfand, 1998). Hofstede, Neuijen, Ohayv, and Sanders (1990) argue that this is in contrast with less economically developed countries of the former Communist block, which represent a collectivistic culture. In these countries, cooperation and group objectives are more important than individual needs and the targets of individual group members. Poland can be located between collectivism and individualism, with a tendency toward individualism due to social and economic changes that took place after regaining its autonomy. 
A distinction between a female and male culture is another factor that differentiates Austria and Poland. According to Hofstede, Hofstede and Minkov (2000), Austria is an example of the "masculine culture" with typical masculine traditions and values, such as order, high efficacy of behavior, competition, individual career and financial success. Poland is less masculine and more "feminine" in nature with a preference for such values as cooperation, mutual understanding, and agreeableness.

\section{Research Focus}

Cultural and demographic differences between the countries may be the source of different socialization patterns, educational standards and demands towards young people. Therefore, an analysis was performed of procrastination behaviors among youths with Polish nationality at different educational stages (secondary schools and high schools), residing and studying in Poland, and among students from the Polish diaspora in Austria. The study aimed at discovering whether gender, age, and different cultural background may be associated with procrastination in the two groups.

\section{Methodology of Research}

\section{General Background of Research}

The present study included Polish students attending secondary and high schools in Lublin, Poland ( $n=101)$ and Polish students born and residing in Vienna, Austria ( $n=105)$. Students from Austria were recruited from the Polish School for Polonia in Vienna, a school established in 1977 by the decree of the Polish Ministry of National Education. Teaching at the school is complementary to compulsory education provided in Austrian schools. The curricula and education stages are the same as in Poland, and comprise primary, secondary, and high schools. Each class met once a week from four to eight p.m. (16:00-20:00) because students from Polonia attend Austrian schools during the day. The school is free of charge and participation is voluntary. All students speak Polish at an advanced level.

\section{Sample of Research}

The age range of the both groups was $12-19$ years $(M=15.18$; $S D=2.05)$, and the number of males and females was very close. The details of demographic variables are presented in Table 1. 
Table 1. Demographic variables

\begin{tabular}{|c|c|c|c|c|c|c|}
\hline & \multicolumn{4}{|c|}{ Gender } & \multirow{2}{*}{\multicolumn{2}{|c|}{ Age }} \\
\hline & \multicolumn{2}{|c|}{ Females } & \multicolumn{2}{|c|}{ Males } & & \\
\hline & $N$ & $\%$ & $N$ & $\%$ & $M$ & $S D$ \\
\hline \multirow[t]{2}{*}{ Austria } & 62 & 59 & 43 & 41 & 15.15 & 2.06 \\
\hline & \multicolumn{6}{|c|}{ Total: 105} \\
\hline Poland & 63 & 62.4 & 38 & 37.6 & 15.64 & 2.07 \\
\hline
\end{tabular}

\section{Instrument and Procedures}

All participants completed the 12-item Pure Procrastination Scale (PPS - Steel, 2010; Polish translation by Stępień, \& Topolewska, 2014) that measured the degree of self-reported academic procrastination. Higher sum scores reflected greater tendency for academic procrastination, the maximum possible score being 60 points. The reliability of the tool was assessed by Cronbach's alpha in the Polish translation version of 0.89 (Stępien \& Topolewska, 2014). With the present samples, alpha was 0.86 .

\section{Procedure}

The studies were conducted in school classrooms after getting the permission for data collection from school authorities. Participants were seated at separate tables, and an informed consent for taking part in the study was obtained from each of them. After reading out the instruction, they were handed PPS test sheets and asked to give answers to all questions. The participation was anonymous, voluntary, and there was no time limit.

\section{Data Analysis}

Because of the broad age range of the participants, two age subgroups were distinguished within both cultural groups. The first subgroups $(n=105)$ encompassed students from $12-15(M=13,23 ; S D=.78)$, i.e. in early adolescence and they all attended secondary schools. The older age group $(n=101)$ included high school students aged 16-19 $(M=16.77 ; S D=1.11)$ (late adolescence).

Since the numbers of participants in each group differed slightly the chisquared test was calculated on their numbers. The obtained score, $\chi^{2}(1)=.078$; 
$p=.780$, showed that those differences in the number of participants within the examined groups were not statistically significant. The homogeneity of the age groups was also confirmed, $\chi^{2}(1)=2.350 ; p=.125$. In addition, homogeneity of the cultural groups, including females as well as males, from both age subgroups in total was measured. Since the number of females was bigger in both groups, a chisquared test was applied. The value of $\chi^{2}$ for the group of females was $\chi^{2}(1)=.008$; $p=.929$; and for the group of males $-\chi^{2}=.309 ; p=.579$, which confirmed their homogeneity. The next step was connected with the choice of adequate statistical procedure; therefore, the distribution of results was evaluated. The Shapiro-Wilk test was administered since number of participants was below 100 in all groups. The data presented in Tables 2 and 3 show that the distribution of scores is skewed.

Table 2. Mean, median, standard deviation, min-max scores, skewness, kurtosis and values of the Shapiro-Wilk test for procrastination

\begin{tabular}{|c|c|c|c|c|c|c|c|c|c|}
\hline & & $M$ & $M e$ & $S D$ & Min & $\operatorname{Max}$ & Skewness & Kurtosis & $W(p)$ \\
\hline \multirow{2}{*}{$\begin{array}{l}\text { Procrastina- } \\
\text { tion }\end{array}$} & A & 30.45 & 30.00 & 8.71 & 15 & 51 & .435 & -.365 & $.970(.017)$ \\
\hline & PL & 33.18 & 33.00 & 9.51 & 13 & 60 & .408 & .047 & $.981(.148)$ \\
\hline
\end{tabular}

$W$ - Shapiro-Wilk test $(\mathrm{N}<100) ; d f_{-} \mathrm{A}=105, d f_{-} \mathrm{PL}=101$.

Table 3. Standard error for skewness and kurtosis

\begin{tabular}{lcc}
\hline & Standard error for skewness & Standard error for kurtosis \\
\hline Austria & .236 & .467 \\
\hline Poland & .247 & .476 \\
\hline
\end{tabular}

\section{Results of Research}

Bedyńska and Cypryańska (2013) advocate the use of parametric tests in such cases, pointing out that the obtained results are plausible. Therefore, the homogeneity of variances in the two main groups was measured by Levene's test $[F(1,204)=.099, p=.753]$. It confirmed the legitimacy of the use of parametric tests in further analyses. The tests were administered in order to discover whether the tendency to procrastinate depended to a greater degree upon gender, age or culture. In addition, interrelations among those variables were measured. 
A multifactorial analysis of variance (ANOVA) for the intergroup plan in the $2 \times 2 \times 2$ scheme was carried out with the use of IBM SPSS Statistics 24 PS IMAGO 4.0. A main effect for the country was only on the level of tendency $[F(1,198)=$ $\left.3.527 ; p=.062, \eta^{2}=.018\right]$. Analysis of the differences between mean scores, with Bonferroni correction for multiple comparisons, showed that students living in Austria had a weaker tendency to procrastinate than those living in Poland ( $M_{-}$A-PL $=-2.248, S E=1.97 ; p=.062)$. The main effect for age was significant $[F(1,198)=$ $\left.7.956 ; p=.005, \eta^{2}=.039\right]$, and analysis of the differences between mean scores, with regard to Bonferroni correction, revealed that the younger students (12-15 years.) procrastinated less than their older colleagues (16-19 years.) $\left(M_{-1-2}=\right.$ $-3.376, S E=1.197 ; p=.005)$. The main effect for gender was not significant $(F<1)$.

An interaction effect for country and age was significant, $F(1.198)=16.274 ; p=$ $.000, \eta^{2}=.076$, for the two main groups, but differed in the age subgroups. It was not significant in the case of the younger group, while in the older group it reached statistical significance, $F(1,198)=15.55 ; p=.000, \eta 2=.073$. This means that Polish students in late adolescence manifested more procrastination behaviors than their Austrian peers. These results are presented in Figure 1.

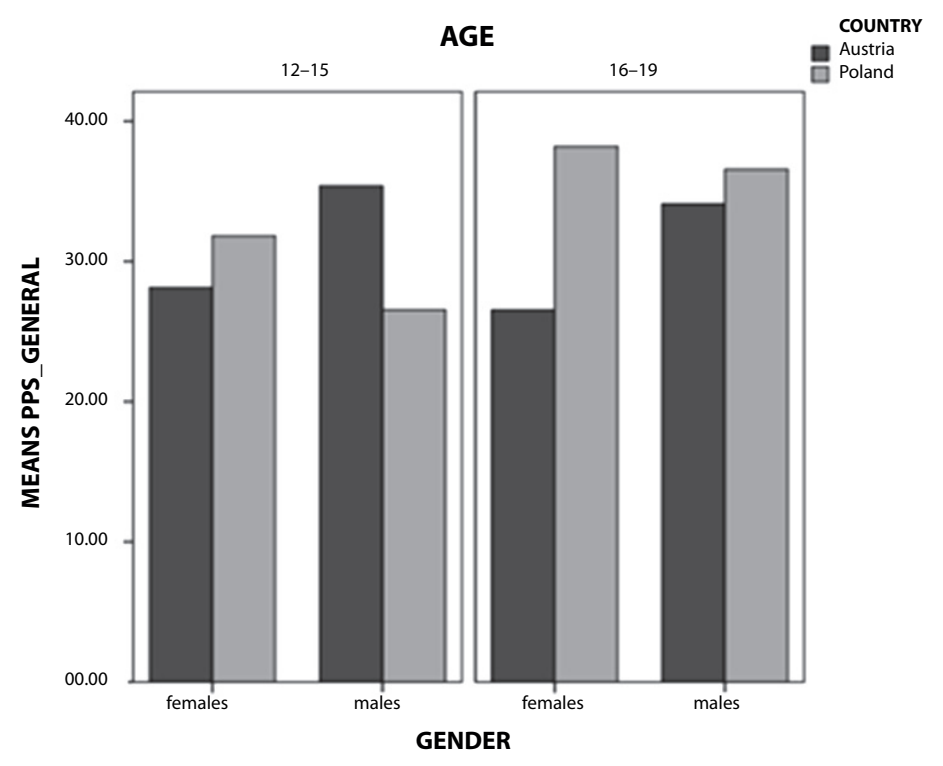

Figure 1. Interaction effect of country and age

The interaction effect for country and gender was also significant for the two main groups, $F(1,198)=20.557 ; p=.000, \eta^{2}=.094$, and was differentiated. It was 
significant in females, $F(1,198)=26.512 ; p=.000, \eta^{2}=.118$, as confirmed by analysis of the differences between the means $\left(M_{-}\right.$females_A-PL $=-7.67, S E=1.49 ; p=$ $.000)$. As presented in Figure 2, young females living in Poland showed a much stronger tendency to procrastinate than the females residing in Austria. Interestingly, the interaction effect for country-gender in males was not significant.

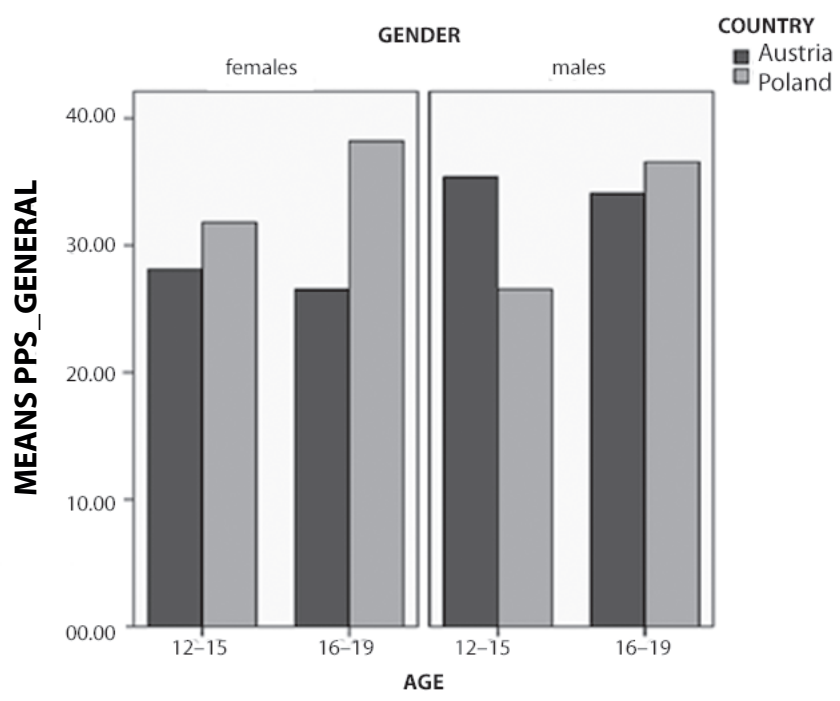

Figure 2. Interaction effect for country and gender

Further analysis of intragroup comparisons revealed that males from Polonia procrastinated more often than females, $F_{-A}(1,198)=20.138 ; p=.000, \eta^{2}=.092$; $M_{-}$A_females-males $=-7.408, S E=1,165 ; p=.000$. On the other hand, the tendency to procrastinate was the reverse in the Polish students, since the females proved to procrastinate more than males $F_{-\mathrm{PL}}(1,198)=3.951 ; p=.048, \eta^{2}=.020$; $M_{\text {PL_females-males }}=3.446, S E=1.734 ; p=.048$.

The last stage of analysis included comparisons of mean scores in order to evaluate the interaction effect for country, gender, and age. The analysis revealed that the procrastination level decreased in late adolescence, both in females and males in the case of Austrian students of the Polish diaspora. The Polish students, however, exhibited an opposite tendency, since the mean level of procrastination was significantly higher in the older age group (Table 4 ). 
Table 4. Mean scores for interaction of country, age and gender

\begin{tabular}{lllccc}
\hline $\begin{array}{c}\text { Dependent } \\
\text { variable }\end{array}$ & Country & Gender & Age groups & M & SD \\
\hline Procrastination & Austria & Females & $12-15$ & 28.135 & 1.357 \\
\cline { 3 - 5 } & & Males & $16-19$ & 26.520 & 1.650 \\
\cline { 3 - 5 } & & $12-15$ & 35.381 & 1.801 \\
\cline { 2 - 5 } & Poland & Females & $16-19$ & 34.091 & 1.759 \\
\cline { 3 - 5 } & & $12-15$ & 31.813 & 1.459 \\
\cline { 3 - 5 } & & Males & $16-19$ & 38.194 & 1.482 \\
\cline { 3 - 5 } & & & $16-19$ & 26.542 & 1.684 \\
\hline
\end{tabular}

\section{Discussion}

The present study showed that both cultural and demographic factors might play a significant role in academic-related procrastination behaviors among emerging adults in a university setting. In general, students living in Poland tended to procrastinate more frequently than the students from the Polish diaspora living in Austria. This result might reflect a respect for work and the ability to organize one's own time and that of others in a country with deeply - rooted Protestant ethics of work among those in the diaspora (Hofstede, Hofstede, \& Minkov, 2000). At the same time, it was found that younger compared to older participants from both countries revealed a lower level of procrastination. Contrary to the common belief that the augmentation of demands may lead to higher procrastination (Ferrari \& Tibbett, 2017), the intergroup analysis revealed that procrastination was significantly higher in the older group of Polish students, whereas it was lower in students from the Polish diaspora in the same age group. It is highly probable that adolescents from Polonia have experienced an intensive educational training in organizing their work, and developing skills to plan their actions in advance.

The significance of demographic factors is attested to by the studies by Ferrari and colleagues (e.g., Argiropoulou, \& Ferrari, 2015; Ferrari, O'Callaghan, \& Newbegin, 2005; Mariani, \& Ferrari, 2012; Steel, \& Ferrari, 2013), which indicated close relationships between procrastination and gender, age, marital status, level of education, and nationality. For instance, Steel and Ferrari (2013) included 16,413 English speaking adults (58.3\% women; $41.7 \%$ men: $M_{\text {age }}=38.3$ years, $S D=14$ ) living in the USA, Australia, New Zealand, Canada, Ireland, United Kingdom, Philippines and Russia. They found that men reported procrastinating more often than 
women. A typical procrastinator was a young, single man with little schooling, who resided in a country with a low level of self-discipline. This outcome confirms the significance of cultural factors (cf. Ferrari, \& Tibbett, 2017).

Further confirmation of the mediating role of culture is provided by differences between the females participating in the present study; namely, the Polish women living in Poland were found to procrastinate more often that those women residing in Austria. Interestingly, no differences were found among males. Is it plausible that Polish young females procrastinate more than females from Polonia because they are allowed to do so.

On the other hand, procrastination behaviors were significantly higher among young men from Polonia than in those males residing in Poland. This finding is in accordance with the study by Klassen et al. (2009) who conducted research on procrastination in a group of 612 adolescents from Canada and Singapore. Those authors not only observed that Singaporean students reported higher levels of procrastination behaviors, but also found that the procrastination level was higher in males than in females in that country. Lower tendency of Turkish females as compared to males to delay tasks was also noted by Karakitapoğlu, \& Imamoğlu (2002). In addition, Ferrari, Callaghan, and Newbegin (2005) reported higher rates of arousal and avoidance procrastination in adults from the United Kingdom than in adults from Australia and the United States. Yet after "pure" procrastination was calculated there was no significant difference across the three countries. It needs to be stressed, however, that those were all English-speaking countries with a similar cultural background.

Taken together, it seems that the strength of one's tendency to procrastinate is culturally bound to a considerable degree. There remain, however, some ambiguities concerning the role of gender and age as most studies were conducted on adults. It is worth pointing out that the research that included emerging adults did find the differences between males and females in their tendency to defer tasks (Argiropoulou, \& Ferrari, 2015). It suggests that procrastination behaviors may be linked to the frontal lobe maturation, and the frontal lobes maturation lag in particular (Gustavson, \& Miyake, 2017; Rabin, Fogel, \& Nutter-Upham, 2011).

\section{Conclusions}

The present study revealed significant differences between the Polish students living in Poland and the students from the Polish diaspora residing in Austria. Generally, the students from the Polish diaspora procrastinated significantly less 
than their Polish peers, and age and gender proved to be important predictors for procrastination behaviors. It was found that Polish students aged between 16-19 procrastinated more often than their Polonia peers from the same age group. Further, the following interrelations among the examined variables were observed:

1) the interaction effect of country and gender for procrastination was differentiated as only Polish girls were found to procrastinate to a higher degree than the girls of the Polish diaspora in Austria;

2) intragroup comparisons revealed a higher tendency to procrastinate in boys than in girls from Polonia, while in the Polish group that tendency was reversed since it was the girls who revealed a higher degree of procrastination behaviors;

3) interaction of country-age-gender revealed a decrease in procrastination with age in the students from Polonia; conversely, the level of procrastination increased in Polish adolescents in the older age group.

It should be stressed that procrastination behaviors in adolescents may influence the educational outcomes. It creates the need to gain better understanding of its causes and manifestations in order to develop programs of overcoming the tendency to procrastinate. Hence, the above-described findings pose a great challenge for both teachers, parents and psychologists.

\section{References}

Argiropoulou, M.I., \& Ferrari, J.R. (2015). Chronic procrastination among emerging adults: factor structure of the Greek version of the General Procrastination Scale. Hellenic Journal of Psychology, 12(2), 85-104.

Bedyńska, S., \& Cypryańska, M. (2013). Drogowskaz statystyczny [Statistical guidance] Warszaw: Wydawnictwo Akademickie Sedno.

Beutel, M.E., Klein E.M., Aufenanger S., Brähler, E., Dreier M., Muller K.W., Quiring O., Reinecke, L., Schmutzer, G., Stark, B., \& Wölfling, K. (2016). Procrastination, distress and life satisfaction across the age range - A German representative community study. PLOS ONE, 11(2): e0148054.

Blunt, A., \& Pychyl, T.A. (2000). Task aversiveness and procrastination: a multidimensional approach to task aversiveness across stages of personal projects. Personality and Individual Differences, 28(1), 153-167.

Compare Countries (2018). Retrieved from: https://www.hofstede-insights.com/country-comparison/austria,poland/.

Evans, D.R., Baer, R.A., \& Segerstrom, S.C. (2009). The effects of mindfulness and self-consciousness on persistence. Personality and Individual Differences, 47(4), 379-382.

Ferrari, J.R., O'Callaghan, J., \& Newbegin, I. (2005). Prevalence of procrastination in the 
United States, United Kingdom, and Australia: Arousal and avoidance delays among adults. North American Journal of Psychology, 7(1), 1-6.

Ferrari, J.R., Özer, B., \& Demir, A. (2009). Chronic procrastination among Turkish adults: Exploring decisional, avoidant, and arousal styles. The Journal of Social Psychology, 149(3), 302-308.

Ferrari, J.R., \& Tibbett, T.J. (2017). Procrastination. In: V. Zeigler-Hill, T.K. Shackelford (Eds.), Encyclopedia of personality and individual differences (pp. 1-8). New York: Springer.

Gustavson, D.E., du Pont, A., Hatoum, A.S., Rhee, S-H., Kremen, W.S., Hewitt, J.K., \& Friedman, N.P. (2017). Genetic and environmental associations between procrastination and internalizing/externalizing psychopathology. Clinical Psychological Science, 5(5), 798-815.

Gustavson, D.E., \& Miyake, A. (2017). Academic procrastination and goal accomplishment: A combined experimental and individual differences investigation. Learning and Individual Differences, 54, 160-172.

Hofstede, G., Hofstede, G.J., \& Minkov, M. (2000). Cultures and organizations. New York: McGraw Hill.

Hofstede, G., Neuijen, B., Ohayv, D.D., \& Sanders, G. (1990). Measuring organizational cultures: A qualitative and quantitative study across twenty cases. Administrative Science Quarterly, 35(2), 286-316.

Karakitapoğlu, A.Z., \& Imamoğlu, E.O. (2002). Value domains of Turkish adults and university students. The Journal of Social Psychology, 142(3), 333-352.

Klassen, R.M., Bong, M., Usher, E.L., Chong, W.H., Huan, V.S., Wong, I.Y. \& Georgiou, T. (2009). Exploring the validity of a teachers' self-efficacy scale in five countries. Contemporary Educational Psychology, 34(1), 67-76.

Mariani, M.G., \& Ferrari, J.R. (2012). Adult inventory of procrastination scale (AIP): A comparison of models with an Italian sample. Testing, Psychometrics, Methodology in Applied Psychology, 19(1), 3-14.

Nomura, M., \& Ferrari J.R. (2018). Factor structure analysis of a Japanese version of the Adult Inventory of Procrastination Scale: Delay is not culture specific. North American Journal of Psychology. 20(1), 223-238

Petrill, S.A. (1997). Molarity versus modularity of cognitive functioning? A behavioral genetic perspective. Current Directions in Psychological Science, 6(4), 96-99.

Rabin, L.A., Fogel, J. \& Nutter-Upham, K.E. (2011). Academic procrastination in college students: the role of self-reported executive function. Journal of Clinical and Experimental Neuropsychology, 33(3), 344-357.

Sirois, F.M. (2004). Procrastination and counterfactual thinking: Avoiding what might have been. British Journal of Social Psychology, 43(2), 269-286.

Steel, P. (2007). The nature of procrastination: A meta-analytic and theoretical review of quintessential self-regulatory failure. Psychological Bulletin, 133(1), 65-94.

Steel, P. (2010). Arousal, avoidant and decisional procrastinators: Do they exist? Personality and Individual Differences, 48(8), 926-934. 
Steel, P., \& Ferrari, J. (2013). Sex, education and procrastination: An epidemiological study of procrastinators' characteristics from a global sample. European Journal of Personality, 27(1), 51-58.

Steel, P., \& König, C.J.(2006). Integrating theories of motivation. Academy of Management Review. 31(4), 889-913.

Steel, P., \& Weinhardt, J. (2018). The building blocks of motivation. Goal Phase System. In: N. Anderson, D.S. Ones, H.K. Sinangil \& C. Viswesveran (Eds.), Handbook of industrial, work \& organizational psychology (Vol. 3, pp. 1-78). Thousand Oaks: Sage.

Stępień, M., \&Topolewska, E. (2014). Style tożsamości w ujęciu Berzonsky’ego a prokrastynacja. [Identity styles according to Berzonsky and procrastination]. Młoda Psychologia, 2, 145-160.

Strenze, T. (2007). Intelligence and socioeconomic success: A meta-analytic review of longitudinal research. Intelligence, 35(5), 401-426.

Tappolet, S. (2010). Procrastination and personal identity. In: C. Andreou, M.D. White (Eds.), The thief of time: Philosophical essays on procrastination (pp. 115-129). New York: Oxford University Press.

Tice, D.M., \& Bratslavsky, E. (2000). Giving in to feel good: The place of emotion regulation in the context of general self-control. Psychological Inquiry, 11(3), 149-159.

Triandis, H.C. (1995). New directions in social psychology. Individualism \& collectivism. Boulder, CO: Westview Press.

Triandis, H.C., \& Gelfand, M.J. (1998). Converging measurement of horizontal and vertical individualism and collectivism. Journal of Personality and Social Psychology, 74(1), 118-128. 